\section{Psychiatry in Russia: economic upturn must bring improvements}

\section{Psiquiatria na Rússia: reforma econômica deverá trazer melhorias}

Throughout the second half of the 20th century, the ways in which the field of psychiatry has been the object of abuse in the former Soviet Union have been widely discussed in the scientific literature. Although this problem has been partially managed in the first decade of the 21st century, it does not mean that it has remained in the past. Note that the systematic abuse of the field of psychiatry is not synonymous with political abuse. Causes of this abusive mishandling may include low standards of training and practice, inadequate quality assurance procedures, ${ }^{1}$ and poorly implemented legislation given that professionals are not trained to use the new laws ${ }^{2}$ and because they are not motivated enough to follow them. We have previously reported a case study ${ }^{3}$ illustrating the overdiagnosis of schizophrenia: the diagnostic criteria of sluggish schizophrenia has been misused in the Soviet Union, thus affecting many people who have nothing to do with politics. Personality disorders, neuroses, reversible disorders seen in adolescence, childhood autism, reactive conditions, etc. have been misdiagnosed and treated as schizophrenia. In the Soviet scientific literature, schizophrenia has been seen as a lifelong process i.e., a disease which remains present in spite of remissions. Consequently, the patients remain registered as schizophrenics at their local psychiatric medical healthcare service units (so-called dispensaries) throughout their entire lives, which can contribute to stigmatization of both patients and their families. In today's Russia, being registered at such services can also result in unemployment because, before hiring, certain employers request a certificate issued by these services. Access to foreign professional literature has always been limited. Meanwhile, differential diagnosis in terms of personality disorders, neuroses and schizophrenia is only vaguely explained in Russian textbooks, thus leaving much room for individual interpretation. Among the prominent Soviet psychiatrists who are responsible for the misuse of the concept of schizophrenia, we find A.V. Snezhnevsky who, in his teachings on "Nosos and Pathos", describes the active process as Nosos and the inherited predisposing constitutional traits as the Pathos of schizophrenia. According to this construct, Nosos can convert into Pathos and vice versa. This is how the disease is mistaken for one's natural way of being, thus allowing for personality disorders and constitutional traits to be diagnosed as schizophrenia. The reason behind the need to preserve this misuse of the diagnostic criteria of schizophrenia is understandable: it makes a physician's everyday practice easier since treating schizophrenia becomes a matter of routine, hence not requiring doctors to innovate; from a legal viewpoint, it is simpler to compulsorily hospitalize. Excess hospitalization of patients with mental disorders has been a common practice. ${ }^{2}$ Living conditions at psychiatric hospitals have been primitive and include overcrowding, lack of privacy, poor hygiene, etc. Now, just as before, the emphasis still remains on the medical aspects of treatment, without appropriately considering social and occupational rehabilitation. ${ }^{4}$ Furthermore, certain publications misplace the focus by debating whether psychiatry alone and not physical medicine is also subjected to abuse. ${ }^{5}$ In fact, while physical medicine can also be abused, psychiatry is especially at risk in certain locations in the world, including the former USSR. For this scenario to change, the first step that needs to be taken includes increased reading of international scientific publications in English and the exchange of professional experience through the implementation of temporary programs for Russian psychiatrists to go abroad and for foreign colleagues to come to Russia.

Sergei V. Jargin

Peoples' Friendship University of Russia, Moscow, Russia

\title{
Disclosures
}

\begin{tabular}{|c|c|c|c|c|c|c|c|}
\hline $\begin{array}{l}\text { Writing group } \\
\text { member }\end{array}$ & Employment & $\begin{array}{c}\text { Research } \\
\text { grant }^{1}\end{array}$ & $\begin{array}{c}\text { Other research grant } \\
\text { or medical continuous } \\
\text { education }\end{array}$ & $\begin{array}{l}\text { Speaker's } \\
\text { honoraria }\end{array}$ & $\begin{array}{c}\text { Ownership } \\
\text { interest }\end{array}$ & $\begin{array}{l}\text { Consultant/ } \\
\text { Advisory } \\
\text { board }\end{array}$ & Other $^{3}$ \\
\hline Sergei V. Jargin & $\begin{array}{l}\text { Peoples' } \\
\text { Friendship } \\
\text { University of } \\
\text { Russia }\end{array}$ & - & - & - & - & - & - \\
\hline
\end{tabular}


References

1. Lavretsky H. The Russian concept of schizophrenia: a review of the literature. Schizophr Bull. 1998;24(4):537-57.

2. Jenkins R, Klein J, Parker C. Mental health in post-communist countries. BMJ. 2005;331(7510):173-4.

3. Jargin SV. Overdiagnosis of schizophrenia: A view from Russia. Asian J Psychiatr. 2009;2(3):119.
4. Jenkins R, McDaid D, Nikiforov A, Potasheva A, Watkins J, Lancashire S, Samyshkin Y, Huxley P, Atun R. Mental health care reforms in Europe: Rehabilitation and social inclusion of people with mental illness in Russia. Psychiatr Serv. 2010;61(3):222-4.

5. Fulford KW, Smirnov AY, Snow E. Concepts of disease and the abuse of psychiatry in the USSR. BrJ Psychiatry. 1993;162:801-10.

\section{Evidence of persistent executive function deficits in cannabis dependence after one month of abstinence}

\section{Evidências de déficits executivos persistentes após um mês de abstinência na dependência de maconha}

FAB SCORE

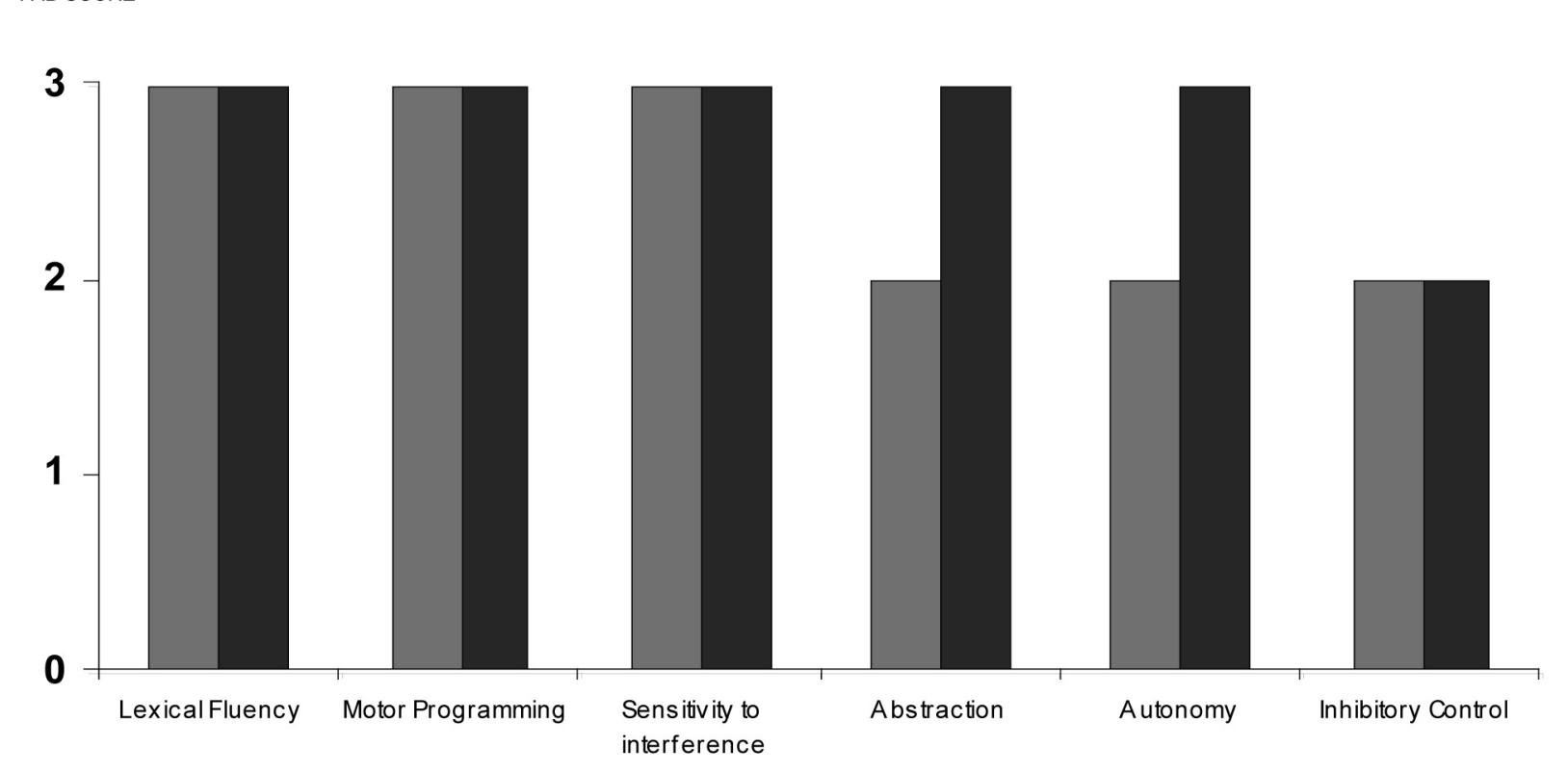

¿ 1st Neuropsychological Assessment (NA)

a 2nd Neuropsychological Assessment (NA)
Dear Editor,

Marijuana is the most commonly used illicit drug around the world. Information about risks is important for prevention and treatment strategies. In this regard, a relevant and well conducted review article was published in the Revista Brasileira de Psiquiatria by Almeida et al., which has concluded that chronic cannabis users (CCU) present executive cognitive functions (ECF) deficits. The authors reviewed nine studies of CCU that showed impaired abstract reasoning, concept formation, and mental flexibility. ${ }^{1}$ ECF may represent a very relevant target for rehabilitation strategies, since ECF deficits are associated with poorer outcomes in treatment. ${ }^{2}$ In addition, the literature discussing whether ECFrelated deficits persist after a period of abstinence is contradictory. ${ }^{3}$ Pope et al. did not find evidences to support that CCU who were 28-day abstinent have persistent ECF-related deficits. ${ }^{4}$

Figure 1 - Executive cognitive functioning in the six domains of the Frontal Assessment Battery (FAB). 